\section{Anaesthesia crisis resource management training: an intimidating concept, a rewarding experience}

Matt M. Kurrek MD, Kevin J. Fish MB ChB FRCPC*
Purpose: This two-part study was performed to identify and address anaesthetists' concerns regarding anaesthesia simulation and to evaluate the response of practitioners to simulation-based Anaesthesia Crisis Resource Management Training (ACRM).

Methods: First, 150 survey questionnaires were distributed to participants of the Anaesthesia Practice '94 meeting in Toronto and to staff and resident anaesthetists at the Sunnybrook Health Science Centre. In the second part of the study, 35 anaesthetists from the Toronto area who participated in Anaesthesia Crisis Resource Management (ACRM) workshops at the Canadian Simulation Centre completed an anonymous exit evaluation questionnaire.

Results: Among staff anaesthetists ( $n=42$ ), 19\% of the surveyed respondents had never heard about anaesthesia simulation, whereas all residents $(n=17)$ had heard of, or seen an anaesthesia simulator. Horizontal numerical scale ratings (from 1-10, with 10 being extremely supportive) indicated support for the purchase of a simulator $(8.3 \pm 2.0$ for staff, 9.2 \pm 1.1 for residents). Staff and residents anticipated substantial anxiety while training with a simulator $(6.8 \pm 2.4$ and $7.6 \pm$ 1.4 respectively, with 10 indicating extreme anxiety). Participants in the ACRM workshops at the Canadian Simulation Centre enjoyed the course $(1.2 \pm 0.6$, on a scale form 1 through 5, with 1 indicating total support and 5 repre.

\section{Key words}

ANAESTHESIA: education;

EDUCATION: simulators, crisis management.

From the Canadian Simulation Centre for Human Performance and Crisis Management Training; Department of Anaesthesia, Sunnybrook Health Science Centre; University of Toronto, Toronto, Canada and Department of Anesthesia, Stanford University Medical Ccnter*, Stanford, CA.

Address correspondence to: Dr. Matt M. Kurrek, Sunnybrook Health Science Centre, Department of Anaesthesia, 2075 Bayview Ave, Toronto, Ontario M4N 3M5, Canada.

Accepted for publication 22nd December, 1995. senting no support), felt that it would be beneficial to most anaesthetists (1.2 \pm 0.5$)$ and should be taken, on average, every $18 \mathrm{mo}$.

Conclusions: Even though the majority of respondents have not been exposed to anaesthesia simulators, they appear to support their use in education strongly. Whereas substantial anxiety could delay the introduction of simulation based education, participants of ACRM workshops enjoy the courses and perceive them as very educational.

Objectif: Cette étude en deux temps a été réalisée dans le but d'identifier et d'évaluer l'importance la préoccupation des anesthésistes en face de la simulation et d'évaluer la réponse des cliniciens à la gestion basée sur la simulation des ressources anesthésiques en situations critiques (ACRM).

Méthodes: Dans un premier temps, 150 questionnaires ont été distribués aux participants au forum d'anesthésie pratique $\dot{a}$ la réunion de 1994 à Toronto et aux membres du service d'anesthésie et aux résidents du Sunnybrook Health Science Centre. Dans un deuxième temps, 35 anesthésistes de la région de Toronto qui participaient à des ateliers d'ACRM au centre canadien de simulation ont complété un questionnaire d'évaluation anonyme à la fin du cours.

Résultats: Parmi les membres du service ( $n=42$ ), $19 \%$ des répondants n'avaient jamais entendu parler en anesthésie de simulateurs, alors que tous les résidents $(n=17)$ en avaient entendu parler ou vus. L'évaluation sur une échelle numérique horizontale (de 0-10,10 = très en faveur) indiquait un soutien à l'achat d'un simulateur $(8,3 \pm 2,0$, pour le personnel, $9,2 \pm$ 1,1 pour les résidents). Le personnel et les résidents appréhendaient un degré important d'anxiété pendant la formation sur le stimulateur (respectivement 6,8 $\pm 2,4$ et 7,6 \pm 1,4, 10 = anxiété extrême). Les participants aux ateliers d'ACRM au centre canadien de simulation ont aimé le cours $(1,2 \pm 0,6$, sur une échelle de $1-5, I=$ très favorable et $5=$ défavorable), pensaient qu'il serait bénéfique à la plupart des anesthésistes $(1,2 \pm 0,5)$ et devrait être répété en moyenne aux 18 mois.

Conclusion: Bien que la majorité des répondants n'aient jamais été exposés à des simulateurs d'anesthésie, il semble qu'il appuient fortement leur utilisation pour la formation. En dépit du 
fait que l'anxiété puisse retarder l'introduction de la formation basée sur la simulation, les participants aux ateliers d'ARCM ont aimé le cours et le perçoivent comme très formateur.

A simulator is a "training device that duplicates conditions likely to be encountered in some operation".' The idea of simulation is not new, and simulators have been part of human training as early as Roman times. ${ }^{2}$ Over the past half-century simulators have changed the training in commercial and military aviation, space flight, fire-fighting and operation of nuclear power plants. ${ }^{3}$ In aviation, most commercial airlines require their pilots to train in "Cockpit Resource Management" using flight simulators with particular emphasis on task-delegation, decision-making, leadership, pilot judgment, communication and crew coordination. ${ }^{4}$ While the impact on aviation safety is difficult to document, the commercial airlines feel that the cost of this training is a worthwhile expenditure in their efforts to improve the safety of air travel.

Similar to the workplace in aviation, the operating room in which anaesthetists work is a complex, dynamic environment, which is known to be crisis prone. ${ }^{5}$ Efforts to improve patient safety have led to increasing attention being focused on the application of the concept of Cockpit Resource Management Training to anaesthesia, where the use of simulators to train anaesthetists in crisis management was pioneered by Gaba. ${ }^{6}$ Two realistic anaesthesia simulation systems are commercially available in North America. Both systems $\left(\mathrm{CAE}^{\circledR}\right.$ Electronics, Loral ${ }^{\oplus}$ Corporation) feature a computer controlled patient mannequin with a variety of physiological functions (e.g., heart and breath sounds, pulse, end-tidal carbon dioxide) that allow patient simulation in an operating room environment. Courses in what is referred to as Anaesthesia Crisis Resource Management (ACRM) training are now being held in several centres in North America.

While pilots are very supportive of simulation-based Cockpit Resource Management Training, anaesthetists' feelings about simulation-based education and ACRM training are not known. In the first part of this study, we assessed anaesthetists' attitudes to an anaesthesia simulator among a group of practitioners with low likelihood of previous simulator experience. In the second part of this study, we collected and analyzed exit evaluations of a second group of anaesthetists after their participation in ACRM workshops.

\section{Methods}

This study was approved by the Sunnybrook Health Science Centre Research Ethics Board. In the first part of this study, 150 survey questionnaires were distributed to participants of the Anaesthesia Practice ' 94 meeting in Toronto and to staff and resident anaesthetists at the Sunnybrook Health Science Centre, University of Toronto. This sample of practitioners had a low likelihood of previous simulator experience, and was chosen to represent a mixture of community-based and academic anaesthetists, and residents in training. An information sheet accompanied the questionnaire to explain details about anaesthesia simulation as well as special features and costs of current simulation systems. The survey was anonymous and was designed to assess practitioners attitudes to an anaesthesia simulator (see Appendix).

In the second part of this study, 36 staff anaesthetists from the University of Toronto Department of Anaesthesia participated in ACRM Workshops at the Canadian Simulation Centre, Sunnybrook Health Science Centre, University of Toronto. The general organization of these workshops was similar to those previously described. ${ }^{6}$ In summary, four to six anaesthetists participated in each course. Following a didactic teaching session about the concepts of ACRM, participants were familiarized with the simulator environment, including the anaesthesia machine, monitors, drug and supply carts. After the familiarization session, a number of events were simulated, during which one of the participants was the primary anaesthetist. When they were not the primary anaesthetist, participants were either observers, ancillary personnel in the operating room, or were waiting in a separate room from which they could be called to help their colleague. Each scenario was videotaped for group review with an instructor in a debriefing session following the simulation, during which salient points relevant to ACRM were emphasized.

At the end of each ACRM workshop, participants were asked to complete the exit evaluation questionnaire as previously described ${ }^{7}$ using a horizontal numerical scale from 1-5 (most to least favourable). The questionnaire examined background, self-evaluation of the participants' response to the simulator, evaluation of the simulator environment, and assessment of the value of the simulator experience to the practice of anaesthesia. Data from these questionnaires were summarized and are presented as mean \pm standard deviation

\section{Results}

\section{Survey questionnaire}

Completed survey questionnaire forms were returned by 59 anaesthetists (see Tables I and II). Seventy one per cent of participants were male, and $29 \%$ female. 
TABLE I Demographics of simulator survey respondents

\begin{tabular}{llc}
\hline & $\begin{array}{l}\text { Staff } \\
(n=42)\end{array}$ & $\begin{array}{l}\text { Residents } \\
(n=17)\end{array}$ \\
\hline Age $(\mathrm{yr})$ & $47 \pm 10$ & $30.3 \pm 3$ \\
Years in practice & $16 \pm 10$ & $3 \pm 2$ \\
Cinadian trained & $94 \%$ & $86 \%$ \\
MOCOMP participation & $43 \%$ & $12 \%$ \\
Awareness about anacsihesia simulation & $81 \%$ & $100 \%$ \\
\hline
\end{tabular}

TABLE II Simulator survey responses

\begin{tabular}{|c|c|c|}
\hline & $\begin{array}{l}\text { Siaff } \\
(n=42)\end{array}$ & $\begin{array}{l}\text { Residents } \\
(n=17)\end{array}$ \\
\hline Supportive of purchase & $8.3 \pm 1.9$ & $9.2 \pm 1.1$ \\
\hline Supportive of training for residents & $8.8 \pm 1.1$ & $9.6 \pm 1.6$ \\
\hline Supportive of training for faculty & $8.1 \pm 1.5$ & $8.4 \pm 1.5$ \\
\hline $\begin{array}{l}\text { Willing to spend unpaid time in the } \\
\text { simulator }\end{array}$ & $8.0 \pm 2.4$ & $9.1 \pm 1.1$ \\
\hline Relcvance of anaesthesia simulation & $8.0 \pm 1.9$ & $9.2 \pm 1.0$ \\
\hline Anxiely associated with simulator training & $6.8 \pm 2.4$ & $7.6 \pm 1.4$ \\
\hline $\begin{array}{l}\text { Support for compulsory use for } \\
\text { recertification }\end{array}$ & $3.6 \pm 2.6$ & $5.6 \pm 1.9$ \\
\hline
\end{tabular}

Horizontal numerical scale ratings (from $1-10$, with 10 bcing extremely supportive) indicated support for purchase of and training in the simulator. Staff and resident anaesthetists anticipated substantial anxicty while training with a simulator $(1-10$, with 10 indicating extremely anxious).

\section{STAFF ANAESTHETISTS}

Seventy three per cent of the respondents were staff anaesthetists $(n=42)$, with a mean age of $47 \pm 10 \mathrm{yr}$ and $16 \pm 10 \mathrm{yr}$ in practice. Eighty-six per cent trained and all practiced in Canada (50\% in a university setting, $50 \%$ in a community hospital). Eighty-three per cent were certified by the Royal College of Physicians and Surgeons of Canada (RCPSC) and 43\% indicated active participation in the maintenance of competence program (MOCOMP) of the RCPSC. Nineteen per cent of the staff had never heard about anaesthesia simulation. One anaesthetist had experienced anaesthesia simulation.

\section{RESIDENTS}

The residents $(n=17)$ had a mean age of $30 \pm 3 \mathrm{yr}$, with $3 \pm 2 \mathrm{yr}$ of residency completed. Ninety-four per cent were in a Canadian residency program, and $12 \%$ were enrolled in MOCOMP. All the residents had heard about anaesthesia simulation, but none had experienced anaesthesia simulation.

\section{SURVEY RESPONSES}

Participants were strongly supportive both of the purchase of a simulator (staff $8.3 \pm 1.9$ and residents $9.2 \pm$ 1.1), and the use of a simulator for training of residents
TABLE III Results of ACRM exit evaluation questionnairc

\begin{tabular}{ll}
\hline Age & $38 \pm 8 \mathrm{yr}$ \\
Easy to treal mannequin as human & $2.0 \pm 0.8$ \\
Debricfing enhanced knowledge & $1.8 \pm 0.6$ \\
ACRM knowledge helpful & $1.3 \pm 0.5$ \\
Enjoyed the course & $1.2 \pm 0.6$ \\
Course would benefit most anaesthetists & $1.3 \pm 0.6$ \\
Course will help to practice more safely & $1.8 \pm 0.9$ \\
Course suited for initial anaesthesia training & $2.9 \pm 1.5$ \\
- for advanced anaesthesia training & $1.3 \pm 0.5$ \\
- for anaesthesia refresher course & $1.5 \pm 0.8$ \\
How often should course be taken & $17 \pm 10 \mathrm{mo}$ \\
\hline
\end{tabular}

Participants enjoyed the course (1-5, with 1 indicating total support and 5 representing no support), felt it would be beneficial to most anaesthetists and should be taken an average of every $18 \mathrm{mo}$.

(staff $8.8 \pm 1.1$, residents $9.6 \pm 1.6$ ) and staff (staff $8.1 \pm$ 1.5 , residents $8.4 \pm 1.5$ ). There was willingness to spend unpaid time training in the simulator (staff $8.0 \pm 2.4$, residents $9.1 \pm 1.1$ ) and simulation based education was felt to be relevant (staff $8.0 \pm 1.9$, residents $9.2 \pm 1.0$ ). Individuals anticipated substantial anxiely while training with a simulator (staff $6.8 \pm 2.4$, residents $7.6 \pm 1.4$ ) and did not support compulsory use for re-certification (staff $3.6 \pm 2.6$, residents $5.6 \pm 1.9$ ). The two most frequent comments related to considerable "fear" and "validation."

\section{ACRM exit evaluation}

Of the 36 participants in the ACRM workshops, 35 returned the exit evaluation questionnaire (Table III). On a horizontal numerical scale (from $1-5$, most to least favourable), candidates indicated that they found it easy to treat the mannequin as human $(2 \pm 0.8)$ and that the new knowledge about ACRM would be helpful (1.3 \pm 0.5 ). They felt that the scenarios they experienced in the ACRM course were situations that they otherwise might not see $(1.7 \pm 1.0)$. The debriefing sessions were an important part of the learning process, and enhanced their knowledge $(1.8 \pm 0.6)$. Overall, the participants enjoyed the ACRM course $(1.2 \pm 0.6)$ and were very positive about the potential benefit of an ACRM course to anaesthetists $(1.3 \pm 0.6)$. They believed that the ACRM course was suitable for both advanced training $(1.3 \pm 0.5)$ and refresher course training $(1.6 \pm 0.8)$. Most participants felt that taking the course would help them to practice anaesthesia more safely $(1.8 \pm 0.9)$ and that the course should be taken on a regular basis (50\% every $12 \mathrm{mo}, 33 \%$ every $24 \mathrm{mo}, 10 \%$ every $6 \mathrm{mo}$ ).

\section{Discussion}

Many studies suggest that a substantial number of aviation accidents are not the result of inadequate flying 
skills but are due to the crew's poor coordination and teamwork, combined with an inability to use available resources. ${ }^{8.9}$ Several larger airlines, together with the National Aeronautics and Space Administration (NASA) jointly developed what is now known as Cockpit Resource Management training. ${ }^{10}$ This has been complemented by the concept of Line Oriented Flight Training in which aircraft crews complete flight segments from take-off until landing in realistic aircraft simulators. This training focuses on delegation of tasks and assignment of responsibilities, team coordination, priority assessment, monitoring/cross checking, use of information, communication, leadership, problem assessment and avoidance of fixation. ${ }^{11}$

Traditional medical school and residency curricula emphasize basic science, applied science and technical knowledge, and do not offer formal training in crisis management. As in aviation, even expert clinicians may not be able to manage critical events optimally because of poor utilization and coordination of available resources. ${ }^{12}$ With the recent availability of realistic patient simulators, the concepts of Cockpit Resource Management and Line Oriented Flight Training have been adapted to ACRM training in anaesthesia, ${ }^{6}$ which is now available at several centres around the world. These centres (including the Canadian Simulation Centre at Sunnybrook Health Science Centre) provide the opportunity to practice specific crisis management skills during simulated events. The simulations are videotaped for subsequent group review led by experienced instructors, providing the opportunity to observe and critique one's own performance from the videotape of the simulation while receiving feedback from other members of the group. This feedback, provided in a supportive and non-judgmental manner, can be a very rewarding experience, but can also be very stressful.

This survey demonstrates that anaesthetists are very supportive of simulation-based training. It is also apparent that anaesthetists are anxious and possibly intimidated by a new tool that may expose deficiencies in a critically important aspect of medical care. The anticipation of anxiely was more concerning to them than considerations about the high cost of an anaesthesia simulator. Perhaps one of the factors influencing these results was an awareness that anaesthesia simulators could be developed into devices for conducting performance evaluations. We would discourage creating such a psychological barrier against simulation-based education by associating simulation with performance evaluation. For this training to be accepted, the "non-judgmental" nature of this concept must be emphasized to practitioners. Realistically, issues of validation and expense make it unlikely that the use of anaesthesia simulators will be a viable option for re-certification. The use of simulation for performance evaluation and re-certification obviously does not enjoy popularity.

This anxiety that practitioners express about simulation-based ACRM training is real and may well be the biggest hurdle to recruiting practitioners to participate in ACRM workshops. These feelings are in contrast to the views of practitioners who have attended an ACRM course, and who enjoyed the courses very much and indicated that they would like to participate in ACRM courses on a regular basis. This aspect can be stressed to future participants in order to ease their fears and encourage them to avail themselves of this promote this valuable educational experience. Another factor that may deter practitioners from participating in an ACRM course is the expense. By the very nature of providing a realistic environment for $A C R M$ training, these courses are both labour-intensive and expensive to run for the limited number of participants who can attend each course.

In summary, although there may be considerable anxiety among practitioners at the thought of taking part in simulator-based ACRM educational programs, the participants who have taken these ACRM courses are very supportive of the value of this training. Acknowledgment of the reality that simulators are unlikely to be developed into tools for performance evaluation will likely reduce this anxiety in prospective participants.

Individuals interested in ACRM workshops should contact Matt M. Kurrek, M.D. (Tel: (416) 480-4864, Email: m.kurrek@utoronto.ca) for a listing of Simulation Centres with available ACRM training courses.

\section{Appendix}

Survey of Anaesthesiologists' attitudes to an anaesthesia simulator

1 What is your age:

2 What is your sex:

$$
\text { male }
$$$$
\text { female }
$$

3 What is your position: faculty/staff resident/fellow

4 If staff, number of years in practice If resident/fellow, numbers of years completed

5 Country of residency training Country of current practice

6 Your practice within the last year was:

_ University based

_ Community based _other, please explain:

7 Are you certified by the RCPSC in anaesthesia?

- Yes

No 
Please mark the following lines to indicate your preference:

8 Do you support the purchase of an anaesthesia simulator to train anaesthesiologists?

$$
\begin{array}{lll}
\text { totally } & 12345678910 & \begin{array}{l}
\text { extremely } \\
\text { unsupportive }
\end{array}
\end{array}
$$

9 How useful do you think anaesthesia simulators would be for RESIDENTS in anaesthesia?
totally
useless
12345678910 extremely
useful

10 How useful do you think anaesthesia simulators would be for FACULTY/STAFF in anaesthesia?
totally
12345678910
extremely
useless
useful

11 How willing would YOU be to spend UNPAID time ( 3 hours) to train with an anaesthesia simulator?
totally
12345678910
extremely
unwilling
willing

12 How relevant do you think time spent training with an anaesthesia simulator would be to YOU?
totally
12345678910
extremely
irrelevant
relevant

13 How much anxiety do you think YOU would experience while training with an anaesthesia simulator?
totally
12345678910
extremely
relaxed
anxious

14 Do you support the COMPULSORY use of anaesthesia simulator for recertification, reaccreditation, or any kind of licensure to practice anaesthesia?

$$
\text { totally } \quad 12345678910 \text { extremely }
$$$$
\text { unsupportive supportive }
$$

Please mark as many as applicable:

15 In your opinion, what would be the important features of an anaesthesia simulator?

_ sharpen my diagnostic skills

_ practice my approach to rare adverse events

— test myself under pressure

_ just for the experience

- other, please explain

16 In your opinion, what would be the important negative aspects of an anajesthesia simulator?

_ lack of realism

- lack of time to spend time with a simulator

_ situation too contrived

_ too much psychological pressure

__ some mishaps cannot be simulated

_other, please explain:

17 Your comments:

18 At the time of completion of this survey:

_ I didn't know anything about the anaesthesia simulators until today
I have heard/read/been lectured about anaesthesia simulators

_I have seen an actual simulator

_ I have actually been in a real simulator as a participant

19 Do you currently participate in the maintenance of competence program of the RCPSC (MOCOMP)?

- Yes

No

\section{References}

1 Webster's New Twentieth Century Dictionary. New York: Simon and Schuster, 1979: 1693

2 Good ML, Gravenstein JS. Anesthesia simulators and training deviccs. Int Anesthesiol Clin 1989; 27: 161-8.

3 Flexman RE, Stark EA. Training simulators, In: Salvendy G. (Ed.). Handbook of Human Factors, New York: John Wiley \& Sons, Inc., 1987: 1022-8.

4 Helmreich RL, Foushee HC. Why crew resource management? Empirical and theoretical bases of human factors training in aviation, In: Wiener EL, Kanki BG, Helmreich RL (Eds.). Cockpit Resource Management, San Diego: Academic Press Inc., 1993: 1-45.

5 Cooper JB, Newbower RS, Long CD, McPeek B. Preventable anesthesia mishaps: a study of human factors. Anesthesiology 1978; 49: 399-406.

6 Howard SK, Gaba DM, Fish KJ, Yang G, Sarnquist FH. Anesthesia Crisis Resource Management Training: teaching anesthesiologists to handle critical incidents. Aviat Space Environ Med 1992; 63: 763-70.

7 Holzman RS, Cooper JB, Gaba DM, Philip JH, Small SD, Feinstein $D$. Anesthesia Crisis Resource Management: real-life simulation training in operating room crises. J. Clin. Anesth 1995; 7: (in press).

8 Ruffell Smith HP. A simulator study of the interaction of pilot workload with errors, vigilance and decisions. (NASA TM-78482). Moffetl Field, CA: NASA-Ames Research Center, 1979: 1-54.

9 Jensen RS, Biegelski CS. Cockpit resource management, In: Jensen RS (Ed.). Aviation Psychology, Aldershot, England: Gower Technical, 1989: 176-209.

10 Lauber.JK. Cockpit resource management: background and overview, In: Orlady HW, Foushce HC. (Eds.). Cockpit Resource Management Training: Proceedings of the NASA/MAC Workshop, 1987: CP-2455.

11 Butler RE. LOFT: Full-mission simulation as crew rcsource management training, In: Wiener EL, Kanki BG, Helmreich RL (Eds.). Cockpit Resource Management, San Diego: Academic Press Inc., 1993: 231-62.

12 DeAnda A, Gaba DM. The role of experience in the response to simulated critical incidents. Anesth. Analg. 1991; 72: 308-15. 